Document downloaded from:

http://hdl.handle.net/10251/61057

This paper must be cited as:

Albiol Pérez, S.; Gil-Gómez, J.; Lloréns Rodríguez, R.; Alcañiz Raya, ML.; Colomer Font, C. (2014). The role of virtual motor rehabilitation: a quantitative analysis between acute and chronic patients with acquired brain injury. IEEE Journal of Biomedical and Health Informatics. 18(1):391-398. doi:10.1109/JBHI.2013.2272101.

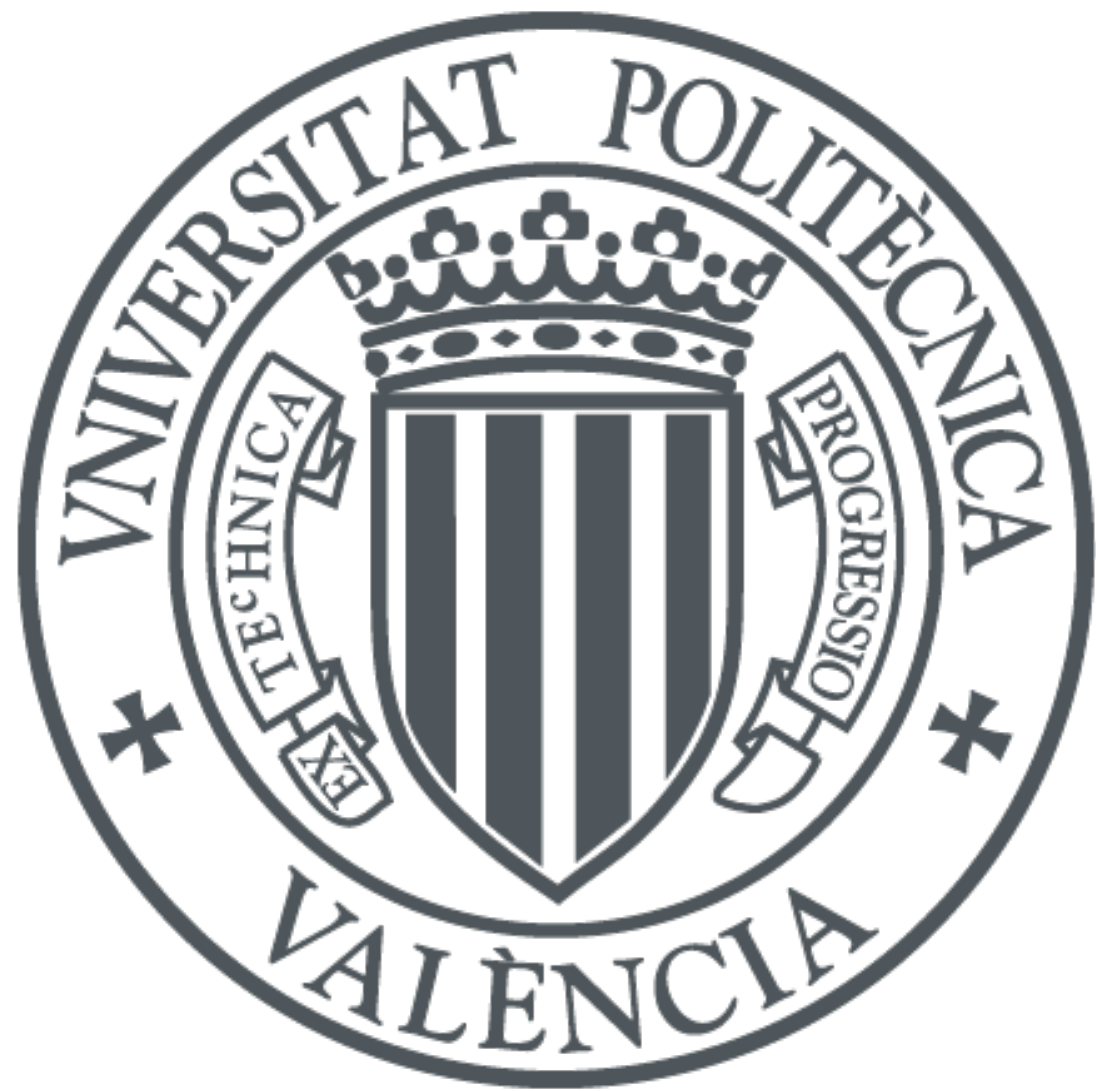

The final publication is available at

http://dx.doi.org/10.1109/JBHI.2013.2272101

Copyright Institute of Electrical and Electronics Engineers (IEEE)

Additional Information

"(c) 2014 IEEE. Personal use of this material is permitted. Permission from IEEE must be obtained for all other users, including reprinting/ republishing this material for advertising or promotional purposes, creating new collective works for resale or redistribution to servers or lists, or reuse of any copyrighted components of this work in other works." 


\section{The role of Virtual Motor Rehabilitation. A quantitative analysis between Acute and Chronic Patients with acquired brain injury.}

Sergio Albiol-Pérez ${ }^{1 * \S}$, José-Antonio Gil-Gómez ${ }^{2 *}$, Roberto Llorens ${ }^{3 *}$, Mariano Alcañiz $^{3 *}$, Carolina Colomer Font, $\mathrm{MD}^{4 *}$

${ }^{1}$ Dpto. de Informática e Ingeniería de Sistemas, Universidad de Zaragoza,

C. Ciudad Escolar S/N, 44003, Teruel, Spain.

${ }^{2}$ Instituto Universitario de Automática e Informática Industrial, Universitat

Politècnica de València, C. Vera S/N, 46022, Valencia, Spain.

${ }^{3}$ Instituto Interuniversitario de Investigación en Bioingeniería y Tecnología Orientada

al Ser Humano, Universitat Politècnica de València, Camino de Vera s/n, 46022

Valencia, Spain.

${ }^{4}$ Servicio de Neurorrehabilitación de los Hospitales NISA. Valencia, Spain.

*These authors contributed equally to this work

${ }^{\S}$ Corresponding author

Email addresses:

SA: $\underline{\text { salbiol@unizar.es }}$

JG: jgil@upv.es

RL: rllorens@labhuman.i3bh.es

MA: $\underline{\text { malcaniz@labhuman.i3bh.es }}$

CC: carol@neurorhb.com 


\section{Abstract}

\section{Background}

Acquired Brain Injury (ABI) is one of the main problems of disability and death in the world. Its incidence and survival rate are increasing annually. Thus, the number of chronic ABI patients is gradually growing. Traditionally, rehabilitation programs are applied to post-acute and acute patients, but recent publications determine that chronic patients may benefit from rehabilitation. Also, in the last few years, the potential of Virtual Rehabilitation systems has been demonstrated. However, until now, no previous studies have been carried out to compare the evolution of chronic patients with acute patients in a Virtual Rehabilitation program. To perform this study, we developed a Virtual Rehabilitation system for ABI patients. The system, Vestibular Virtual Rehabilitation (V2R), was designed with clinical specialists. V2R has been tested with 21 people ranging in age from 18 to 80 years old that were classified in two groups, chronic patients and acute patients. The results demonstrate a similar recovery for chronic and acute patients during the intervention period. Also, the results showed that chronic patients stop their improvement when they finish their training. This conclusion encourages us to direct our developments towards VR systems that can be easily integrated at home, allowing chronic patients to have a permanent VR training program. 


\section{Keywords}

Virtual Motor Rehabilitation, Virtual Reality, Acute/Chronic Acquired Brain Injury, Balance rehabilitation.

\section{Background}

One of the main causes of disability and death nationwide is Acquired Brain Injury

(ABI). Worldwide, the estimated incidence of ABI in 2007 was 101 cases per 100,000 individuals [1]. During the period 1995-2006, around 10 million people in the United States suffered ABI every year [2,3,4]. European ABI incidence is estimated to be 235 per 100,000 population per year. [5]. The incidence and survival rate of ABI patients is increasing annually $[2,6]$, so the number of patients that need rehabilitation therapies is gradually increasing. Moreover, since ABI is the leading cause of disability in children and young adults [6], many people have to suffer years of physical and cognitive problems after ABI.

The main physical problems that follow an ABI are spasticity, muscle weakness, limited movements and coordination $[7,8,9]$. The consequences derived from these problems are limited postural control, gait deficits and fall risk [10].

These drawbacks significantly reduce the ability of the subjects to perform activities of daily living (ADL) $[11,12,13,14]$ such as personal hygiene, eating, dressing, and walking $[15,16]$.

Traditional motor rehabilitation in $\mathrm{ABI}$ is focused on the recovery of postural control and limb coordination to reduce instability and risk of fall [14]. To achieve this, traditional motor rehabilitation is based on the repetition of specific movements. This type of rehabilitation is tedious, monotonous, and boring.

New emerging technologies such as Motor Virtual Rehabilitation (MVR) provide new features to apply in traditional rehabilitation. Many studies have shown the 
advantages of these systems over traditional rehabilitation $[17,18,19,20]$. MVR usually includes a game approach that engages patients and minimizes boredom, increasing their motivation and adherence to treatment. Another important advantage of many MVR systems is the objective location of a body part in real time [21,22] or even the location of their Center-of-Pressure (COP) $[23,24]$. This data allows the adjustment of MVR systems to different patients in real-time. Also, this data can be recorded to provide important information about the progression of patients.

Force Platforms (FP) are used in balance recovery and postural control due to their capacity to accurately measure the COP of the patient [25]. FP allows the assessment and rehabilitation of balance $[26,27]$. Traditionally, the drawback of FP has been the high cost.

New peripherals originally designed for videogame consoles offer new and interesting possibilities in Virtual Rehabilitation Therapies. The Nintendo® WBB is a widely available popular low-cost FP, that can be used in these types of therapies. To date, different studies have demonstrated the validity of the WBB in balance rehabilitation $[28,29,30,31]$ and assessment $[23,24]$. A good example of this WBB-based system is presented by Kennedy et al. [32]:"WeHab" is a system that provides visual feedback of the COP of the patient for balance rehabilitation in stroke acute patients. The system is used in exercises such as sit-to-stand, weight transferences and stepping. Based on the time post injury [13], ABI patients are classified in three groups: postacute (0-5 months post injury), acute (6-23 months post injury) and chronic (24 months or more post injury). As Babikian and Asarnow explain [13], the greatest functional impairments are observed in the post-acute period, the greatest recovery is achieved in the acute period and most of the recovery has already taken place and relatively little change is expected in the chronic period. 
Because of this, traditional rehabilitation is focused mainly on post-acute and acute ABI patients.

However, the increasing incidence and survival rate of ABI patients produce an increase in chronic patients. This requires a new approach for chronic patients. Therefore, a change is occurring, and new proposals for rehabilitation also demonstrate their suitability for chronic patients [33,34]. An example of this type of rehabilitation is Geurtsen et al. [35]. They evaluated employability, community integration, work hours, and Quality of life (QOL) of chronic ABI patients. Gupta et al. [36] assessed functional results in chronic ABI patients and conclude that patients of this type continue to show functional recovery with adequate rehabilitation even in the chronic phase.

Cameirao et al. [42] revealed significant improvements in upper extremity functional recovery in patients with chronic stroke. You et al. [43] demonstrated an improvement in cortical reorganization and consequent motor recovery using MVR in chronic stroke patients. Kim et al. [44] also demonstrated that MVR can provide advances in balance and gait function in chronic stroke patients. Cho et al. [45] achieved a significant improvement in dynamic balance in chronic stroke patients using virtual reality balance training.

In this paper, we present a study that evaluates balance rehabilitation in acute and chronic patients with a virtual rehabilitation system. To our knowledge, this is the first study that evaluates the effectivity of a virtual rehabilitation program for balance recovery in chronic patients, comparing their evolution with acute patients. To carry out the rehabilitation we use a WBB-based virtual rehabilitation system that was specifically designed for recovery from balance disorders. In the clinical study, we evaluated patients before the rehabilitation process, after the rehabilitation process, 
and one month after the end of the rehabilitation process (follow-up evaluation). Follow-up analysis after VR training $[40,41]$ is critical, and the therapist needs to study the long-term efficacy, which is one of the main challenges in the rehabilitation process of $\mathrm{ABI}$ patients.

\section{Methods}

\section{Virtual Rehabilitation System}

The MVR used for the current study was the Vestibular Virtual Rehabilitation (V2R) system. The V2R system can be installed on a standard PC running under Microsoft ${ }^{\circledR}$ Windows ${ }^{\circledR} \mathrm{XP} / 7$. Weight transferences are achieved through a commercial force platform, the Nintendo ${ }^{\circledR}$ Wii Balance Board ${ }^{\circledR}(\mathrm{WBB})$. This board has four points of pressure that allow the COP of the subject to be calculated. A wireless Bluetoothbased communication is set-up to transfer data from the WBB to the V2R System. A Full HD LCD/LED TV is recommended for visualization. A 42- or 47-inch screen is perfect for patients, and it can be easily integrated in the clinical environment using a Flat TV trolley floor stand with wheels at the bottom, which allows it to be moved around easily. A 2.1 speaker system is used, helping users to locate a sound source (left / right) if necessary. V2R was developed in lite-C [46] using Gamestudio/A8. V2R was developed to improve postural control in TBI patients through the interaction with different virtual games in the standing/sitting position (Figure 1).

$<$ Here Figure 1>

Clinical specialists actively participated in the design of the system. The system has also been developed considering the guidelines described in other WBB-based virtual rehabilitation systems with proven efficacy $[28,37]$. As the system has been designed for clinical purposes, it prevents the risk of injury that is related to commercial games (e.g. metatarsal avulsion fracture [38] or lateral patella dislocation [39]). Another 
interesting contribution of the designed system is the use of positional auditory cues to provide positional information.

In the virtual rehabilitation process with V2R, therapists commonly use four stages of the system, in the following order: 1) Menu module; 2) Calibration module; 3) Virtual Games module; 4) Global Results module.

The Menu module shows the different games of the system. This module allows therapists to select games for a wide range of patients (a total of six possibilities). Two possibilities are designed to be played in the sitting position, with associated medio-lateral and Antero Posterior weight transferences. Four possibilities are designed for standing training; patients could train lateral transferences and Antero Posterior transferences (with the patient in the tandem position -one foot in front of the other-). There is also a game designed to rehabilitate the sit-to-stand movement. The Calibration module allows the system to control the weight distribution limits of the patients (see Figure 2). This module is very important because it permits the system to adapt to the level of impairment of every patient in every session.

\section{$<$ Here Figure 2>}

This module can measure different weight distribution limits of a patient: 1) Lateral weight transferences in the standing and sitting position; 2) Antero Posterior weight transferences in the sitting position; 3) Antero Posterior weight transferences in the tandem position (standing, one foot in front of the other). The module also registers the weight of the patient (to control the sit-to-stand movement). Thus, according to these weight distributions, V2R calibrates and stores the limits required in games previously selected by the therapist for the active session.

In the standing static position, WBB can be placed in two different positions: the standing position and the tandem standing position. In the sitting position, the patient 
sits on the WBB. In the standing dynamic position the WBB is placed in front of the patient and he has to step to the left or to the right, depending on the target.

In the calibration module, V2R shows the weight distribution in real time, providing feedback to the patient and the therapist. (see Figure 2).

In the Virtual Games Module, the patient plays games previously selected by the therapist in the Menu Module. V2R offers a total of six different possibilities, with five games: a game for Antero Posterior and lateral weight transferences in the sitting position, a game for Antero Posterior weight transferences in the tandem position, a game for lateral weight transferences in the standing position, a game for the sit-tostand movement, and a game for lateral weight transferences, which are valid for the sitting and standing position.

The description of these games can be found in Table 1 .

$<$ Here Table 1>

All games are automatically adapted in every session according to the calibration records.

The Global Results module (see Figure 3) displays the results of the last three sessions. Here, the patient and the therapist can see the general results (percentage of hits) and the evolution of the patient in relation to their weight transferences in different situations -standing/sitting, Antero Posterior/lateral.

$<$ Here Figure 3>

\section{Subjects/Participants}

The inclusion criteria were: 1 ) age $\geq 18$ years and $\leq 80$ years; 2 ) chronicity: in acute patients, this is between 6 and 23 months; in chronic patients, this is more than 24 months; 3) patients without severe, moderate, or mild cognitive impairment(MiniMental state examination (MMSE)>24 [47]); 4) comprehension of V2R instructions 
(Mississippi Aphasia Screening Test (MAST) $\geq 45$ [48]); 5) balance and postural control disorders due to acquired brain injury (Berg Balance Scale Test results [49] (BBS) in acute patients between 20 and 52). The exclusion criteria were: 1) patients with visual/auditory injuries that cannot interact correctly with V2R system;2) patients with hemispatial neglect;3) patients with ataxia; 4) unsolved trauma injuries. The final sample consisted of 21 people (13 men and 8 women) classified in two groups: Chronic and Acute Patients. The acute patient group was composed of 7 men and 4 women ranging in age from 21 to 77 years old $(50.27 \pm 15.82)$ and a mean chronicity of $12.51 \pm 4.73$ months. The pathology of acquired brain injury in this group included severe traumatic brain injury (TBI) $(n=1)$ and ischemic or hemorrhagic stroke $(n=10)$. The chronic patient group was composed of 6 men and 4 women ranging in age from 29 to 60 years old $(45.50 \pm 11.18)$ and a mean chronicity of $88.40 \pm 35.39$ months. The pathology of traumatic brain injury in chronic patients was TBI $(n=3)$, ischemic or hemorrhagic stroke $(n=5)$, anoxia $(n=1)$ and tuberculous meningitis $(\mathrm{TB})(\mathrm{n}=1)$. The information of the subjects is shown in Table 2 (acute and chronic patients).

$<$ Here Table 2>

\section{Rehabilitation session/Rehabilitation process}

The study was carried out in two locations: the neurorehabilitation service of a large metropolitan hospital and the facilities of an Association for the Care of Disabled Persons. The acute and chronic patients performed a total of 20 rehabilitation sessions, distributed in 3-5 sessions per week. The time of the sessions for patients was 30 minutes playing with V2R.

When necessary before the session, the therapist explained a set of basic instructions to perform the exercises correctly. 
Each session (see Figure 4) was composed of different stages: 1) games selection; 2) calibration stage; 3 ) virtual rehabilitation stage (patients interacted with three virtual games and they had two specific rest periods between virtual games). At the end of the session, the patients needed a special final rest period to recover. During this final rest period, the patient and the therapist can see the results, and discuss the patient's evolution in the last three sessions.

$<$ Here Figure 4>

Also, after the first session, the therapist gives the patients a modified usability questionnaire (SUS) [50] in order to measure the usability and patient satisfaction with V2R. This questionnaire is composed of 10 statements, with a five-point Likert scale (from 1 "Strongly disagree" to 5 "Strongly agree"), which was adapted for ABI patients. The adaptation of the questionnaire was supervised by a therapist and a specialist in usability.

\section{Data Analysis}

The analysis was carried out by the use of repeated measure analyses of variance (ANOVAs) with Group (Between Subjects, the groups are acute and chronic patients), with Time (Within Subjects), and with Group-by-Time. $p<0.05$ was taken as significant in each case. Demographical and clinical analyses were carried out with independent sample t-test and Chi-squared test. All the analyses were generated using IBM SPSS 19 (IBM Corporation, USA) on a standard PC.

The work plan includes three evaluation stages: 1) Initial Evaluation, at the beginning of the clinical trial; 2) Final Evaluation, at the end of the clinical trial; 3) Follow-up evaluation, one month after the final evaluation.

For each stage (Initial Evaluation, Final Evaluation, and Follow-up Evaluation), we carried out the following clinical tests: the Berg Balance Scale (BBS) [49], the Time 
"Up and Go" Test (TUG) [51,52], 30-second Sit-to-Stand Test (30SST) [53], the Paretic Stepping Test (ST paretic) [54], the non-Paretic Stepping Test (ST nonparetic) [54], the Sitting Anterior Reach Test (ART sitting) [55] and the Standing Anterior Reach Test (ART standing) [55].

\section{Results}

The analysis of the demographic factor is shown in the Table 2 for Acute/Chronic Patients. No significant differences in demographical (age or gender) or clinical variables were detected in either group. As expected, we found significant differences between Acute/Chronic Patients in "Time since injury" ( $p=0.000)$.

With regard to clinical tests, the repeated ANOVA measures were carried out for the two sub-periods (the rehabilitation period (T0-T1) and after the rehabilitation period (T1-T2) in order to evaluate when group-by-time and/or time effect are significant. The results are shown in Table 3 and Figure 5.

$<$ Here Figure 1>

$<$ Here Table 2>

\section{Berg Balance Scale}

The BBS [49] is designed to measure balance through a 14-item scale questionnaire; each item is quantified by a five-point attitude Likert scale (from 0 to 4 ). ANOVA results reveal a significant difference for the acute and chronic groups in time effect $(\mathrm{p}<0.01)$ in the sub-period T0-T1, and a significant group-by-time effect $(\mathrm{p}<0.01)$, and a significant time effect $(\mathrm{p}<0.01)$ in the sub-period T1-T2.

\section{Time "up and go" test}

The TUG [51] was designed to obtain the time that patients used to stand up from a chair, walk a distance of $3 \mathrm{~m}$, turn around, return, and sit-down on the chair. This clinical test is related to of dynamic balance. 
ANOVA results show a significant difference for the acute and chronic groups in time effect $(\mathrm{p}=0.022)$ in the sub-period T0-T1, and a significant group-by-time effect $(\mathrm{p}<0.01)$ in the sub-period T1-T2.

\section{0-Second Sit-to Stand test}

The 30SST [53] measures the number of times from sitting to standing position in 30 seconds, using a stool without back support. Full movement is composed of the series sitting-standing-sitting.

In the sub-period (T0-T1), ANOVA results show a significant difference for the acute and chronic groups in time effect $(\mathrm{p}<0.01)$, and in group-by-time effect $(\mathrm{p}<0.033)$. No significant differences were found in the sub-period (T1-T2).

\section{Stepping test}

The ST paretic and non-paretic [54] measure the number of repetitions for 15 seconds that the patient carries out to place one foot (paretic and non-paretic in different sessions) onto a $7.5 \mathrm{~cm}$ high step and then back down to the floor.

For paretic limb (ST paretic), in the sub-period (T0-T1), the ANOVA results show a significant difference for acute and chronic groups in time effect $(\mathrm{p}<0.01)$, and a significant group-by-time effect $(\mathrm{p}<0.01)$. In the sub-period $(\mathrm{T} 1-\mathrm{T} 2)$, there is a significant group-by-time effect $(\mathrm{p}<0.01)$.

For non-paretic limb (ST non-paretic) the ANOVA results indicate a significant difference for acute and chronic groups in time effect $(\mathrm{p}<0.01)$ in the first sub-period (T0-T1).

\section{Anterior Reach test sitting}

The ART for sitting and standing [55] measures the furthest distance that the patient is able to reach beyond arm's length without moving his feet (in the stability limits) in the standing or sitting position. 
In the sub-period (T0-T1), there is no significant difference between groups in the ART sitting. In the sub-period (T1-T2), the ANOVA results show a significant difference for the acute and chronic groups in group-by-time effect $(\mathrm{p}=0.016)$ for this test.

\section{Anterior Reach test standing}

In the both sub-periods (T0-T1 and T1-T2), there is no significant difference between groups in the ART standing.

\section{Discussion}

Balance impairment is one of the most common problems of ABI patients, and it affects ADL decisively [14]. Traditionally rehabilitation therapies are focused on post-acute and acute patients. Following some studies [13], chronic patients are not considered because the greatest functional recovery is done in the first 24 months post injury. However the number of chronic ABI patients is growing annually $[1,6]$. Fortunately, a change is taking place. In the last few years, research studies on motor rehabilitation in chronic $\mathrm{ABI}$ patients demonstrate that functional recovery is possible for these patients $[33,34,35,36]$.

The purpose of this study was to analyze and to test balance rehabilitation in acute and chronic patients using a customizable virtual rehabilitation system based on a previous system with proven clinical efficacy [28]. The results suggest that balance recovery is possible for chronic patients. Most of the clinical measures demonstrate a recovery for chronic patients similar to the recovery of acute patients during the intervention period, without significant differences between groups. During the intervention period (T0-T1), both groups show significant improvement in BBS. No significant differences in the group effect are detected in this period; therefore, according to the BBS, our results confirm the balance recovery 
independently of the chronicity of the patients. In the follow-up period (T1-T2), the results obtained in BBS show significant group-by-time effect, demonstrating that acute patients continue with their recovery after the rehabilitation program, while chronic patients do not significantly continue their recovery.

The TUG, results show significant improvement for acute patients in both sub-periods (T0-T1 and T1-T2). However, chronic patients do not show any improvement, and they even get worse results. To interpret these results, it is necessary to remember what is measured by the TUG test. The TUG is designed to assess mobility, and dynamic balance is a key factor for this test. The V2R system is designed to recover static balance more specifically than dynamic balance or other complex motor tasks; therefore, no improvement was expected for this test before the study. The chronic patients confirm our expectations, but the acute patients do not. We consider that the improvement of the acute patients was due to their chronicity because acute patients are in the period where spontaneous recovery is more likely. In the 30SST, both groups improved their results in the intervention period (T0-T1). The V2R system has a module to specifically train the sit-to-stand movement, which is the core of the 30SST. In this first sub-period, the results demonstrate a greater improvement in the acute group than in the chronic group. This may be due to the greater potential of recovery of acute patients for this movement. In the follow-up period (T1-T2) there was no significant improvement in either group. Therefore, the improvement registered in the first period is related to the intervention with the V2R system.

In the V2R system, there is also a module to train the capacity of patients to step one foot fully on and then off of a block step (specifically the WBB, which is a $5.32 \mathrm{~cm}$ high step). That justifies the good results for the intervention period (T0-T1) obtained 
in both groups in the Stepping Tests carried out (ST paretic and ST non-paretic). After the intervention, no significant improvement was registered in either group (neither ST paretic nor ST non-paretic) for the follow-up period; therefore, improvement in the first period can be associated with the V2R system.

No significant improvement over time was detected for the ART (ART sitting and ART standing) in either group in any sub-period. The skills directly measured by this test are not specifically trained by the V2R system; therefore, this result is expected. In any case, for ART, the results of the acute patients over time were slightly better than the results of the chronic patients. Again, the reason could be related to chronicity: the acute patients are in a period where spontaneous recovery is more probable.

\section{Conclusions}

This study was done to analyze the effects of VMR in acute and chronic patients. To achieve this, we have created a novel and customizable virtual rehabilitation system using a low-cost device such as the WBB. The different modules of the system were designed following recommendations and suggestions of clinical specialists. In the last few years, the literature has demonstrated the effectiveness of virtual rehabilitation. This study corroborated this evidence. The improvement of the patients is specially reflected in the clinical tests that evaluate tasks that are closely related to the movements trained directly with the system. Many other previous studies also documented this conclusion $[9,18,20,28]$. Thus, the results suggest that a wider range of modules in the VR system -to rehabilitate more tasks- would benefit patients. With regard to chronicity, two important conclusions can be obtained from the study. First, the results demonstrated that chronic patients can benefit from VR training in a way similar to acute patients. However, this assertion is valid only for tasks that are 
closely related to the skills trained in the VR modules. In other tasks, acute patients can also show improvement (they are still in a spontaneous recovery period), but chronic patients do not improve significantly.

A second important conclusion is related to the follow-up of chronic patients. The results showed that chronic patients stop their improvement, or even lose part of this improvement, when they finish their VR training. Posterior follow-up evaluations would be interesting to confirm this trend. This conclusion encourages us to direct our developments towards VR systems that can be easily integrated at home, allowing chronic patients to have a permanent VR training program.

Nevertheless, considering the size (a total of 21 patients, 10 chronic) and the characteristics of our sample, the conclusions should be carefully considered. A larger sample will reinforce these interesting conclusions.

With regard to adherence to the program, the patients reported great motivation during the program due to the recreational approach of the VR system. This feature has been referenced widely in the literature $[22,29,32]$ as one of the main advantages of Virtual Rehabilitation. Patients did not suffer from cyber side effects when playing with the VR system, which reinforces the adherence to the treatment.

Therapists also emphasize the ease and speed of use of the application. This is because the system has been specifically designed to be quickly integrated in the daily clinical routine.

Currently, the clinical centers involved in the study integrated the VR system as part of their routine, and they have encouraged us to develop new modules to promote improvement in other skills (such us upper limb rehabilitation or dynamic balance activities). 
We are now involved in the development of new VR modules following the conclusions and clinical suggestions of this study.

\section{Authors' contributions}

SA, JG, RL, and MA were involved in the design, development and the analysis of the final results. CC participated in the design of the study and carried out the data collection of the chronic and acute patients and their final interpretation. All of the authors have read and reviewed the final manuscript.

\section{Acknowledgements}

The authors acknowledge the study done by the team and the acute patients of the Servicio de Daño Cerebral from the Hospital Valencia al Mar and the team and chronic patients of Instituto Valenciano de Atención a las personas con Discapacidad y Acción Social, especially Dr. Enrique Noé.

\section{References}

1. E.J. Shiroma, P.L. Ferguson and E.E. Pickelsimer, "Prevalence of Traumatic Brain Injury in an Offender Population: A Meta-Analysis," J Correct Health Care, vol. 27, pp. 147-159, Apr. 2010.

2. M. Faul, L. Xu, M.M. Wald and V.G. Coronado, "Traumatic brain injury in the United States: emergency department visits, hospitalizations, and deaths 2002-2006," Atlanta (GA): Centers for Disease Control and Prevention, National Center for Injury Prevention and Control, CDC report, pp.7, 2010.

3. V.G. Coronado, L. Xu, S.V. Basavaraju, L.C. McGuire, M.M. Wald, M.D. Faul, B.R. Guzman, J.D. Hemphill and Centers for Disease Control and Prevention (CDC), "Surveillance for traumatic brain injury-related deaths-United States, 1997-2007,’. MMWR Surveill Summ, vol. 60, pp. 1-32, May 2011 
4. J.A. Langlois, W. Rutland-Brown and M.M. Wald, "The epidemiology and impact of traumatic brain injury: a brief overview," J Head Trauma Rehabil, vol. 21, pp. 375-378, Sep-Oct 2006.

5. F. Tagliaferri, C. Compagnone, M. Korsic, F. Servadei and J. Kraus, “A systematic review of brain injury epidemiology in Europe," Acta Neurochir, vol. 148, pp. 255-268, 2006.

6. World Health Organization, "Neurological_disorders_report_web. Neurological Disorders, Public Health Challenges, 3.1,” pp. 164-176.

7. F. Soyuer and A. Ozturk, "The effect of spasticity, sense and walking aids in falls of people after chronic stroke," J Disabil Rehabil, vol. 29, pp. 679-687, 2007.

8. A.G. Andersson, K. Kamwendo, A. Seiger and P. Appelros, "How to identify potential fallers in a stroke unit: validity indexes of 4 test methods," J Rehabil, vol. 38, pp. 186-191, 2006.

9. K.I. Ustinova, W.A. Leonard, N.D. Cassavaugh and C.D. Ingersoll, "Development of a 3D immersive videogame to improve arm-postural coordination in patients with TBI," J Neuroeng Rehabil, vol. 8, 2011.

10. R. Teasell, M. McRae, N. Foley and A. Bhardwaj, "The incidence and consequences of falls in stroke patients during inpatient rehabilitation: factors associated with high risk," Arch Phys Med Rehabil, vol. 83, pp. 329-333, 2002.

11. D. Hyndman, A. Ashburn and E. Stack, "Fall events among people with stroke living in the community: circumstances of falls and characteristics of fallers," Arch Phys Med Rehabil, vol. 83, pp. 165-170, 2002. 
12. M.C. Dault and C. Dugas, "Evaluation of a specific balance and coordination program for individuals with a traumatic brain injury," Brain Inj, vol. 16, pp. 231-244, 2002.

13. T. Babikian and R. Asarnow, "Neurocognitive outcomes and recovery after pediatric TBI: meta-analytic review of the literature," Neuropsychology, vol. 23, pp. 283-296, 2009.

14. A. Nardone, M. Godi, A. Artuso, M. Schieppati, "Balance rehabilitation by moving platform and exercises in patients with neuropathy or vestibular deficit," Arch Phys Med Rehabil, vol. 91, pp. 1869-1877, 2010.

15. D. Hyndman, A. Ashburn, "People with stroke living in the community: attention deficits, balance, ADL ability and falls," Disabil Rehabil, vol. 25, pp. 817-822, 2003.

16. K. Brandt and M.A. Paniagua, "The Use of Nintendo Wii with Long-Term Care Residents," J Am Geriatr Soc, vol. 59, pp. 2393-2395, 2011.

17. G. Saposnik, M. Levin and Outcome Research Canada (SORCan) Working Group, "Virtual reality in stroke rehabilitation: a meta-analysis and implications for clinicians," Stroke, vol. 42, pp. 1380-1386, 2011.

18. M.S. Cameirão, S.B. Badia, E.D. Oller and P.F. Verschure, "Neurorehabilitation using the virtual reality based Rehabilitation Gaming System: methodology, design, psychometrics, usability and validation," $J$ Neuroeng Rehabil, vol. 7, 2010.

19. N. Mumford, J. Duckworth, P.R. Thomas, D. Shum, G. Williams and P.H. Wilson, “Upper-limb virtual rehabilitation for traumatic brain injury: A preliminary within-group evaluation of the elements system," Brain Injury, vol. 26, pp. 166-76, 2012. 
20. B. Lange, S. Koenig, C.Y. Chang, E. McConnell, E. Suma, M. Bolas and A. Rizzo, “Designing Informed Game-Based Rehabilitation Tasks Leveraging Advances in Virtual Reality," Disability and Rehabilitation, vol. 34, pp. 186370, 2012.

21. L. Zimmerli, C. Krewer, R. Gassert, F. Müller, R. Riener, L. Lünenburger, "Validation of a mechanism to balance exercise difficulty in robot-assisted upper-extremity rehabilitation after stroke," J Neuroeng Rehabil, vol. 3, 2012.

22. G. Saposnik, R. Teasell, M. Mamdani, J. Hall, W. McIlroy, D. Cheung, K.E. Thorpe, L.G. Cohen and M. Bayley, "Effectiveness of virtual reality using Wii gaming technology in stroke rehabilitation: a pilot randomized clinical trial and proof of principle," Stroke, vol. 41, pp. 1477-1484, 2010.

23. R.A. Clark, A.L. Bryant, Y. Pua, P. McCrory, K. Bennell and M. Hunt, "Validity and reliability of the Nintendo Wii Balance Board for assessment of standing balance," Gait Posture, vol. 31, pp. 307-310, 2010.

24. R.A. Clark, R. McGough and K. Paterson, "Reliability of an inexpensive and portable dynamic weight bearing asymmetry assessment system incorporating dual Nintendo Wii Balance Boards," Gait Posture, vol. 34, pp. 288-291, 2011.

25. A. Kalron, Z. Dvir and A. Achiron, "Effect of a cognitive task on postural control in patients with a clinically isolated syndrome suggestive of multiple sclerosis,” Eur J Phys Rehabil Med, vol. 47, pp. 579-586, 2011.

26. M. Sobera, B. Siedlecka and M. Syczewska, "Posture control development in children aged 2-7 years old, based on the changes of repeatability of the stability indices," Neurosci Lett, vol. 491, pp. 13-17, 2011. 
27. Y.H. Ju, I.S. Hwang and R.J. Cherng, "Postural adjustment of children with spastic diplegic cerebral palsy during seated hand reaching in different directions," Arch Phys Med Rehabil, vol. 93, pp. 471-479, 2012.

28. J.A. Gil-Gómez, R. Lloréns, M. Alcañiz and C. Colomer, "Effectiveness of a Wii balance board-based system (eBaViR) for balance rehabilitation: a pilot randomized clinical trial in patients with acquired brain injury," J Neuroeng Rehabil, vol. 23, 2011.

29. C.H. Shih, L.C. Chen and C.T. Shih, "Assisting people with disabilities to actively improve their collaborative physical activities with Nintendo Wii Balance Boards by controlling environmental stimulation," Res Dev Disabil, vol. 33, pp. 39-44, 2012.

30. C.H. Shih, "A standing location detector enabling people with developmental disabilities to control environmental stimulation through simple physical activities with Nintendo Wii Balance Boards," Res Dev Disabil, vol. 32, pp. 699-704, 2011.

31. J.F. Esculier, J. Vaudrin, P. Bériault, K. Gagnon and L.E. Tremblay, "Homebased balance training programme using Wii Fit with balance board for Parkinsons's disease: A pilot study," J Rehabil Med, vol. 44, pp. 144-150, 2012.

32. M.W. Kennedy, J.P. Schmiedeler, A.D. Striegel, C.R. Crowell, M. Villano and J. Kuitse, "Enhanced Feedback in Balance Rehabilitation using the Nintendo Wii Balance Board," e-Health Networking Applications and Services (Healthcom), 2011 13th IEEE International Conference on. 2011, pp. 162168. 
33. D. Hoofien, A. Gilboa, E. Vakil and P.J. Donovick, "Traumatic brain injury (TBI) 10-20 years later: a comprehensive outcome study of psychiatric symptomatology, cognitive abilities and psychosocial functioning," Brain Inj, vol. 15, pp.189-209, 2001.

34. G.J. Geurtsen, C.M. van Heugten, R. Meijer, J.D. Martina and A.C. Geurts, "Prospective study of a community reintegration programme for patients with acquired chronic brain injury: effects on caregivers' emotional burden and family functioning," Brain Inj, vol. 25, pp. 691-697, 2011.

35. G.J. Geurtsen, C.M. van Heugten, J.D. Martina, A.C. Rietveld, R. Meijer and A.C. Geurts," Three-year follow-up results of a residential community reintegration program for patients with chronic acquired brain injury," Arch Phys Med Rehabil, vol. 93, pp. 908-911, 2012.

36. A. Gupta and A.B. Taly, "Functional outcome following rehabilitation in chronic severe traumatic brain injury patients: A prospective study," Ann Indian Acad Neurol, vol. 15, pp. 120-124, 2012.

37. W. Young, S. Ferguson, S. Brault and C. Craig, "Assessing and training standing balance in older aldults: A novel approach using the 'Nintendo Wii' Balance Board," Gait Posture, vol. 33, pp. 303-305, 2011.

38. K.A. Eley, “A Wii fracture,” N Engl J Med, vol. 362, pp. 473-474, 2010.

39. R.J. Robinson, D.A. Barron, A.J. Grainger and R. Venkatesh, "Wii knee," Emerg Radiol, vol. 15, pp. 255-257, 2008.

40. A.S. Merians, H. Poizner, R. Boian, G. Burdea and S. Adamovich, "Sensorimotor training in a virtual reality environment: does it improve functional recovery post-stroke?," Neurorehabil Neural Repair, vol. 20, pp. 252-267, 2006. 
41. J. Broeren, M. Rydmark, A. Björkdahl and K.S. Sunnerhagen, “Assessment and training in a 3-dimensional virtual environment with haptics: a report on 5 cases of motor rehabilitation in the chronic stage after stroke," Neurorehabil Neural Repair, vol. 21, pp. 180-189, 2007.

42. M.S. Cameirão, S.B. Badia, E. Duarte, A. Frisoli and P.F. Verschure, "The Combined Impact of Virtual Reality Neurorehabilitation and Its Interfaces on Upper Extremity Functional Recovery in Patients With Chronic Stroke," Stroke, vol. 43, pp. 2720-2728, 2012.

43. S.H. You, S.H. Jang, Y.H. Kim, M. Hallett, S.H. Ahn, Y.H. Kwon, J.H. Kim and M.Y. Lee, "Virtual reality-induced cortical reorganization and associated locomotor recovery in chronic stroke: an experimenter-blind randomized study," Stroke, vol. 36, pp. 1166-1171, 2005.

44. J.H. Kim, S.H. Jang, C.S. Kim, J.H. Jung and J.H. You, “Use of virtual reality to enhance balance and ambulation in chronic stroke: a double-blind, randomized controlled study," Am J Phys Med Rehabil, vol. 88, pp. 693-701, 2009.

45. K.H. Cho, K.J. Lee and C.H. Song, "Virtual-reality balance training with a video-game system improves dynamic balance in chronic stroke patients,“ Tohoku J Exp Med, vol. 228, pp. 69-74, 2012.

46. Conitec Gamestudio. Available: http://www.conitec.net/english/gstudio/index.php.

47. M.F. Folstein, S.E. Folstein and P.R. Mchugh, ”Mini-Mental State: a practical method for grading the cognitive state of patients for the clinicians," $J$ Psychiatr Res, vol. 12, pp. 189-198, 1975. 
48. R. Nakase-Thompson, E. Manning, M. Sherer, S.A. Yablon, S.L. Gontkovsky and C. Vickery, "Brief assessment of severe language impairments: initial validation of the Mississippi aphasia screening test,“"Brain Inj., vol. 19, pp. 685-691, 2005.

49. K.O. Berg, S.L. Wood-Dauphinee, J.I. Williams and B. Maki, "Measuring balance in the elderly: validation of an instrument," Can Jl of Public Health, vol. 83, pp. 7-11, 1992.

50. J. Brooke, "SUS: a ‘quick and dirty’ usability scale,” In P. W. Jordan, B. Thomas, B. A. Weerdmeester, \& A. L. McClelland. Usability Evaluation in Industry, London: Taylor and Francis, 1996.

51. D. Podsiadlo and S. Richardson, "The time "up \& go": a test of basic functional mobility for frail elderly persons," J Am Geriatr Soc, vol. 39, pp. 142-148, 1991.

52. T.M. Steffen , T.A. Hacker and L. Mollinguer, "Age- and gender-related test performance in community-dwelling elderly people: six-minute walk test, Berg balance scale, timed up \& go test, and gait speeds," Phys Ther, vol. 82, pp. 128-137, 2002.

53. O. Verschuren, M. Ketelaar, T. Takken, M. Van Brussel, P.J. Helders and J.W. Gorter, "Reliability of hand-held dynamometry and functional strength tests for the lower extremity in children with cerebral palsy," Arch Phys Med Rehabil, vol. 88, pp. 32-36, 2007.

54. K.D. Hill, J. Bernhardt, A.M. McGann, D. Maltese and D. Berkovits, “A new test of dynamic standing balance for stroke patients: reliability, validity and comparison with healthy elderly," Physiother Can, vol 48, pp. 257-262, 1996. 
55. P.W. Duncan, D.K. Weiner, J. Chandler and S. Studensk,'Functional reach: a new clinical measure of balance," J Gerontol 1990, vol. 45, pp. 192-197, 1990.

\section{Figures}

\section{Figure 1 - Patients playing with the system}

The image was taken from Acute and Chronic TBI Patients playing with V2R. Antero Posterior and medio-lateral weight transferences were carried out using the Nintendo® Wii Balance Board®, a standard PC and a Full HD LCD/LED TV.

\section{Figure 2 - Calibration of V2R in the standing position}

The dial movement in the standing and sitting position is based on weight transferences of $\mathrm{ABI}$ patients.

\section{Figure 3 - Global Results}

The global results module displays the results of the last three sessions, such as date of the session, percentage of hits, and weight transferences in the standing/sitting position.

\section{Figure 4 - Flow of the Game}

The flow of the game can be divided into: 1) Setup; 2) Calibration; 3) Gameplay; 4) Break; 5) Final Scores.

\section{Figure 5 - Clinical test results.}

In Figure 5, the box-plot shows the results of the clinical test: A) measurement of the levels of ability in a specific task in the standing and sitting position (BBS); B) measurement of basic functional mobility (TUG); C) the maximum distance that ABI patients can extend their hands forward in the sitting position (ART Sitting); D) the maximum distance that $\mathrm{ABI}$ patients can extend their hands forward in the standing 
position (ART Standing); E) measurement of dynamic motor exercises using paretic foot (ST Paretic), F) measurement of dynamic motor exercises using non-paretic foot (ST non-paretic); G) times from sitting to standing in 30 seconds (30SST).

\section{Tables}

Table 1 - Virtual Games of V2R

\section{Sitting Position}

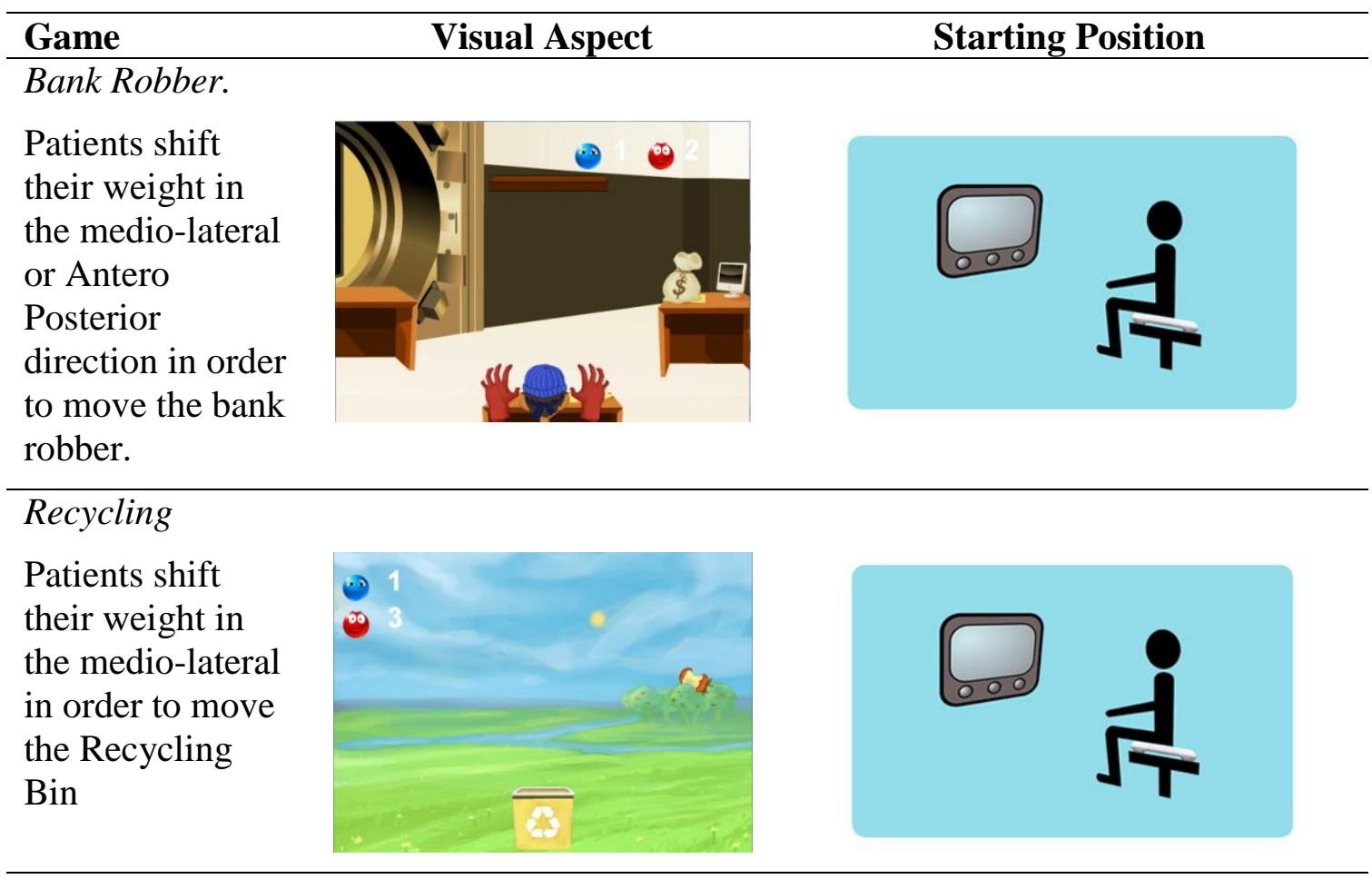

\section{Standing Position}

\begin{tabular}{lll}
\hline Game & Visual Aspect & Starting Position \\
\hline
\end{tabular}

Fireman

Patients move the hose to the fire by shifting their weight from foot to foot, forwards and backwards.
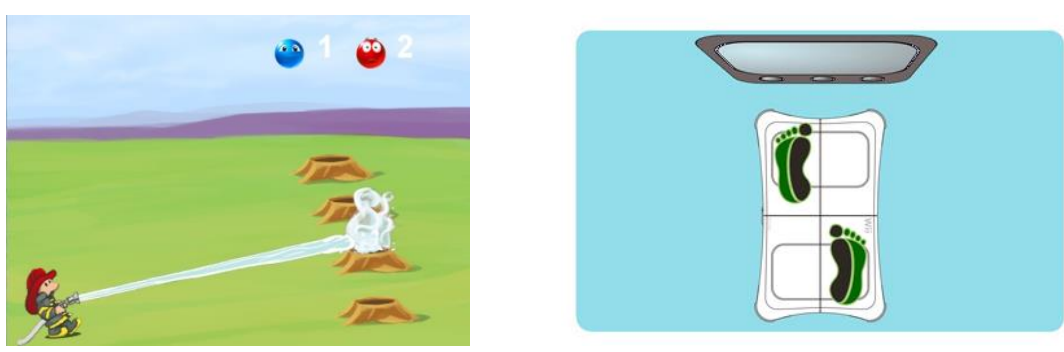

\section{Jungle}

Patients move the truck from left to right by shifting their weight to the 


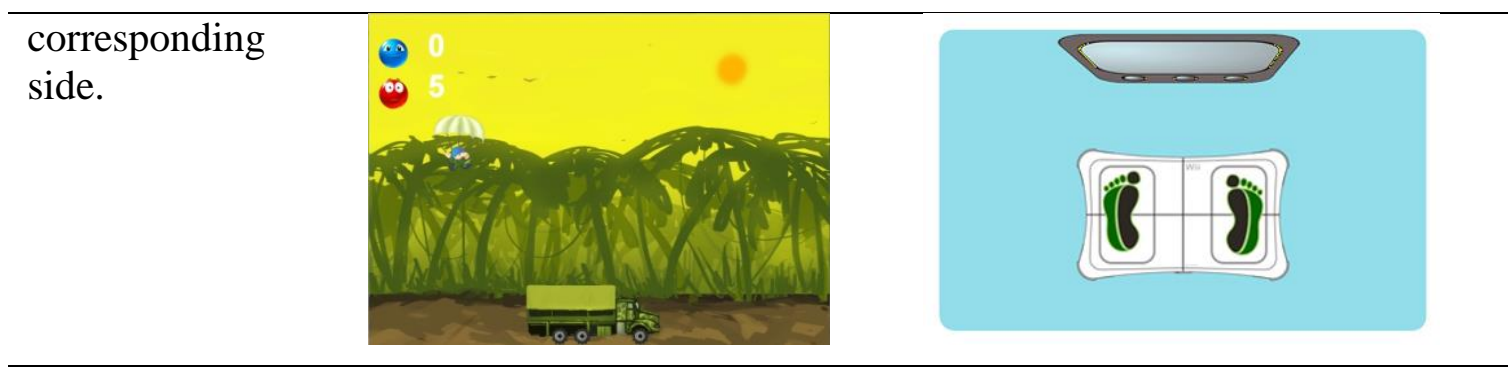

\section{Fruit Game}

Patients move the basket into different positions on the screen: top or bottom, depending on whether the subject is standing or seated.
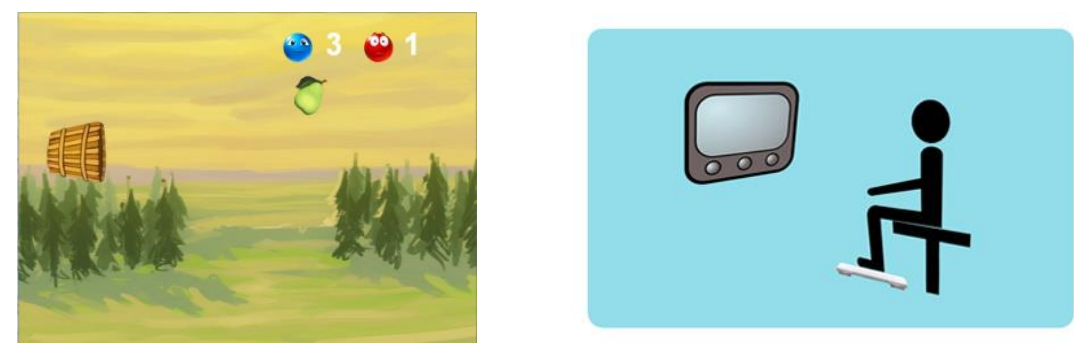

\section{Other Snapshots}

Menu
First, V2R
displays the
menu screen to
select the right
video games for
the actual
session.




\section{Table 2 - Characteristics of the Patients}

This table shows the information of the acute and chronic patients grouped by gender and pathology. The global results (age and time since injury) are expressed by the mean and standard deviation. The pathology shows the main types of acquired brain injury: Stroke, Acquired Brain Injury, and others such as ataxia. NS: non-significant S: significant.

\begin{tabular}{lccc}
\hline Issue & Acute & Chronic & Significance \\
& Patients & Patients & \\
\hline Gender $(n)$ & $7(33.3 \%)$ & $6(28.6 \%)$ & NS (p=0.872) \\
Male & $4(19.1 \%)$ & $4(19.1 \%)$ & \\
Female & $\mathbf{5 0 . 2 7} \pm \mathbf{1 5 . 8 2}$ & $\mathbf{4 5 . 5 0} \pm \mathbf{1 1 . 1 8}$ & NS (p=0.439) \\
\hline Age $($ years $)$ & & & NS (p=0.069) \\
\hline Pathology $(n)$ & $10(47.6 \%)$ & $5(23.8 \%)$ & \\
Stroke & $1(4.8 \%)$ & $3(14.3 \%)$ & \\
TBI & 0 & $2(9.5 \%)$ & \\
Other & $\mathbf{1 2 . 5 1 \pm 4 . 7 3}$ & $\mathbf{8 8 . 4 0} \pm \mathbf{3 5 . 3 9}$ & \\
\hline Time since injury & & & \\
(months) & & & \\
\hline
\end{tabular}

Table 3 - Acute/Chronic Patients: Clinical data

Numerical data of the scores of the scales and tests. The results are given in terms of mean $(\overline{\mathrm{X}})$ and standard deviation $(\sigma)$. The sub-indexes 0 and 20 represent the assessments carried out between Initial Evaluation and Final Evaluation. G: group effect. T: time effect. GxT: group/time effect. ${ }^{*} \mathrm{p}<0.05$, ${ }^{*} \mathrm{p}<<0.01$. T0 represents Initial Evaluation, T1 represents Final Evaluation, and T2 represents Follow-up Evaluation. 


\begin{tabular}{|c|c|c|c|c|c|}
\hline & $\begin{array}{c}\text { Initial } \\
\text { Evaluation } \\
\left(\bar{X}_{0} \pm \sigma_{0}\right)\end{array}$ & $\begin{array}{c}\text { Final } \\
\text { Evaluation } \\
\left(\bar{X}_{20} \pm \sigma_{20}\right)\end{array}$ & $\begin{array}{l}\text { Follow-up } \\
\text { Evaluation } \\
(\Delta \bar{X} \pm \Delta \sigma)\end{array}$ & $\begin{array}{c}\text { Significance } \\
\text { T0-T1 } \\
\text { Evaluation }\end{array}$ & $\begin{array}{c}\text { Significance } \\
\text { T1-T2 } \\
\text { Evaluation }\end{array}$ \\
\hline \multicolumn{6}{|l|}{$B B S$} \\
\hline Acute & $38,82 \pm 9.85$ & $43.55 \pm 8.78$ & $45.73 \pm 7.82$ & $\mathrm{~T}^{* *}(\mathrm{p}=0.000)$ & $\mathrm{T}^{* *}(\mathrm{p}=0.001)$ \\
\hline Chronic & $45.30 \pm 6.20$ & $48.70 \pm 5.79$ & $49.00 \pm 5.81$ & & $\operatorname{GxT}^{* *}(\mathrm{p}=0.009)$ \\
\hline \multicolumn{6}{|l|}{$T U G(s)$} \\
\hline Acute & $29.13 \pm 19.66$ & $23.32 \pm 15.71$ & $18.91 \pm 11.68$ & $\mathrm{GxT}^{*}(\mathrm{p}=0.027)$ & $\mathrm{GxT}^{* *}(\mathrm{p}=0.008)$ \\
\hline Chronic & $28.60 \pm 26.56$ & $32.30 \pm 35.01$ & $33.17 \pm 35.92$ & & \\
\hline \multicolumn{6}{|l|}{$30 S S T(n)$} \\
\hline Acute & $6.27 \pm 3.52$ & $10.64 \pm 5.18$ & $11.91 \pm 5.02$ & $\mathrm{~T}^{*}(\mathrm{p}=0.000)$ & NS \\
\hline Chronic & $9.20 \pm 4.18$ & $11.00 \pm 4.80$ & $11.30 \pm 5.27$ & $\mathrm{GxT}^{*}(\mathrm{p}=0.033)$ & \\
\hline \multicolumn{6}{|l|}{ ST paretic } \\
\hline Acute & $4.36 \pm 3.88$ & $6.82 \pm 4.07$ & $7.45 \pm 4.27$ & $\mathrm{~T}^{*}(\mathrm{p}=0.000)$ & $\mathrm{GxT}^{* *}(\mathrm{p}=0.002)$ \\
\hline Chronic & $5.80 \pm 4.44$ & $10.70 \pm 4.67$ & $8.80 \pm 4.59$ & $\mathrm{GxT}^{* *}(\mathrm{p}=0.004)$ & \\
\hline \multicolumn{6}{|c|}{ ST non-paretic } \\
\hline Acute & $5.90 \pm 3.81$ & $8.18 \pm 4.28$ & $7.54 \pm 4.34$ & $\mathrm{~T}^{* *}(\mathrm{p}=0.000)$ & NS \\
\hline Chronic & $6.80 \pm 3.64$ & $9.40 \pm 4.74$ & $10.00 \pm 4.57$ & & \\
\hline \multicolumn{6}{|l|}{$A R T$ sitting } \\
\hline Acute & $37.18 \pm 10.25$ & $39.86 \pm 10.73$ & $41.36 \pm 10.33$ & NS & $\mathrm{GxT}^{*}(\mathrm{p}=0.016)$ \\
\hline Chronic & $36.45 \pm 4.17$ & $38.40 \pm 6.92$ & $35.80 \pm 8.56$ & & \\
\hline \multicolumn{6}{|c|}{ ART standing } \\
\hline Acute & $26.64 \pm 6.43$ & $30.14 \pm 7.69$ & $31.09 \pm 7.69$ & NS & NS \\
\hline
\end{tabular}


